\title{
LA SITUACION JURIDICA DEL INSTITUIDO FRENTE A LA FACULTAD DE DISPOSICION ONEROSA DEL INSTITUYENTE EN EL PACTO SUCESORIO CON EFICACIA POST MORTEM
}

\author{
María Elena Alonso Rodríguez
}

\begin{abstract}
Sumario: I. Introducción. II. El Pacto Sucesorio. II.1. Regulación legal. Naturaleza jurídica y clases. II.2. Arraigo histórico de la institución. II.3. Libertad de testar en el Código Civil. III. Regulación legal del pacto Sucesorio en Vizcaya. III.1. Regulación anterior: Ley de 30 de julio de 1959. La Compilación de Derecho Civil Foral de Vizcaya y Alava. III.2. Regulación Actual. Ley 3/1992, de 1 de junio, del Derecho Civil Foral del País Vasco. IV. La sucesión contractual en los demás Derechos forales. IV.1. Ley 15/1967, de 8 de abril, sobre Compilación del Derecho Civil de Aragón. IV.2. Decreto Legislativo 79/1990, de 6 de septiembre, por el que se aprueba el Texto Refundido de la Compilación del Derecho Civil de las Islas Baleares. IV.3. Ley 1/1973, de 1 de marzo, por la que se aprueba la Compilación del Derecho Civil Foral de Navarra. IV.4. Ley 40/1991, de 30 de diciembre. Código de Sucesiones por causa de muerte en el Derecho Civil de Cataluña. IV.5. Ley 147/1963 de 2 de diciembre, sobre Compilación del Derecho Civil de Galicia. IV.6. Conclusión. V. Análisis de la cuestión en el Derecho civil común. V.1. El Legado. V.1.1. El legado frente al pacto sucesorio. V.1.2. La transformación y la enajenación en la institución del legado. V.1.2.1. La transformación. V.1.2.2. La enajenación. V.2. Confrontación de la teoría de la transformación y enajenación del legatario y legado con las facultades de disposición del instituyente en el pacto sucesorio (art. 78.2 Ley 3/1992). V.2.1. Las facultades de disposición del instituyente. V.2.2. Voluntad del instituyente como manifestación tácita de revocación e ineficacia del pacto sucesorio. V.2.2.1. La transformación. V.2.2.2. La enajenación. V.2.2.3. Acciones del instituido. VI. Conclusiones. VI.1. Análisis de los supuestos desde la propia institución del pacto sucesorio. Espíritu del legislador. VI.2. Análisis de la cuestión en relación con la regulación del contrato en el Código Civil. VI.3. Conclusiones en torno a la actual regulación legal de la institución. Bibliografía.
\end{abstract}




\section{Introducción}

Hay que ser consciente y partir del hecho de que el pacto sucesorio no ha tenido una regulación escrita hasta la actual Ley 3/1992, pero no es menos cierto que la vigente Ley de Derecho Civil Foral del País Vasco se realizó de una manera poco sosegada y, tal y como se indica en la propia Exposición de Motivos, es una reforma urgente.

El presente estudio pretende analizar la suficiencia de la regulación legal de las disposiciones onerosas que la ley vigente permite al instituyente en el pacto sucesorio con eficacia post mortem, y las situaciones con que puede encontrarse el instituido por esta libertad de disposición.

Piénsese que por pacto sucesorio se nombra al instituido sucesor en una masa patrimonial concreta, y el hecho de que, como veremos, el instituyente tenga la propiedad de los bienes y la ley le permita disponer de ellos a título oneroso, puede provocar situaciones cuando menos peculiares.

Por esta capacidad de disposición, el instituyente puede modificar o enajenar el bien objeto de pacto, teniendo eficacia éste tras su fallecimiento. Así, podría el instituyente trasformar esa masa patrimonial de manera que el caserío que deja al instituido pase a ser un alojamiento de agroturismo, o el pequeño supermercado o tienda de ultramarinos en una parafarmacia. También puede suceder que el instituyente enajene el bien de manera que el pabellón industrial de una pequeña empresa siderometalúrgica, por ejemplo, se convierta en un almacén de productos de todo a cien; o la tintorería pase a ser una sucursal bancaria.

En todos estos casos, ¿en qué situación queda el instituido tras la muerte del ascendiente respecto de tales disposiciones? ¿Qué es lo que realmente percibiría? ¿Podría entenderse revocado el pacto? Y, si así fuera, ¿qué acciones judiciales podría tener contra el instituyente? ¿Podría pedir daños y perjuicios por esa variación realizada y sobre la que nada puede decir ¿En qué supuestos?

A tal fin se va a proceder, tras una sucinta exposición de la institución, una contraposición con los diferentes principios que rigen en ella y en el Código Civil y enunciar la regulación legal, a un análisis de otros Derechos civiles especiales que nos permitan observar si existe alguna regulación legal en este supuesto y de qué modo se lleva a cabo.

Posteriormente, se realizará un análisis de otras instituciones del Código Civil que por su similitud o naturaleza nos permitan hallar soluciones a los interrogantes planteados. Así, se examinará el legado, sobre todo los supuestos regulados en los apartados primero y segundo 
del art. 869 C.C., esto es, la transformación y enajenación, para confrontar dichas disposiciones con las que se permiten en el pacto sucesorio objeto de estudio, y comprobar si se pueden trasladar plenamente o no, y finalmente respecto del contrato regulado en el Código Civil como solución más satisfactoria.

\section{EI Pacto Sucesorio}

\section{II.1. Regulación legal. Naturaleza jurídica y clases}

La primera vez que aparece el pacto sucesorio en la Ley 3/1992 es en el art. 27 (Título III - «De las Sucesiones») cuando establece que la designación del sucesor de bienes «tiene lugar por testamento, ley, por pacto sucesorio, capitulaciones matrimoniales o escritura de donación».

En principio, de la enumeración a que se refiere el precepto referido podríamos pensar que el pacto sucesorio es un instrumento diferente de las capitulaciones matrimoniales o escritura de donación.

Nada más lejos de la realidad, ya que el Capítulo IV del mismo Título III, se intitula «De los pactos sucesorios» estableciéndose en el art. 74 que «mediante capitulaciones matrimoniales, donación o pacto otorgado en escritura pública se puede disponer la sucesión de los otorgantes (...)», es decir, que el pacto sucesorio es un concepto genérico que comprende tanto las capitulaciones matrimoniales, la donación o cualquier otro contrato que persiga la misma finalidad, a saber, la designación del sucesor en los bienes.

Por tanto, el pacto sucesorio es una institución de Derecho civil vasco para designar al sucesor en los bienes que puede llevarse a cabo a través de los diferentes instrumentos enumerados (capitulaciones matrimoniales, donaciones u otros contratos), realizados siempre en escritura pública.

En lo que respecta a su naturaleza jurídica, el pacto sucesorio es una institución sucesoria inter vivos, un contrato entre el causante y heredero en el que pactan la sucesión y las condiciones que van a regir en tal contrato instituido. Por tanto, como tal contrato es un acto bilateral, sinalagmático y personalísimo, ya que el instituido ha sido elegido por sus cualidades personales. Y es irrevocable, siendo necesaria la concurrencia de ambas partes para su modificación (a diferencia del testamento que al ser un acto unilateral puede ser variado en cualquier tiempo y lugar). Es por eso, que se le aplican las mismas normas que a los contratos, exigiéndose en este caso la instrumentación en escritura pública. 
Los pactos sucesorios pueden ser a título universal o a título singular para bienes concretos y determinados.

A tenor de sus efectos los podemos clasificar en: post mortem, cuando la eficiencia acontece con la muerte del instituyente; o de eficacia de presente, en cuyo caso el instituido adquiere la propiedad de los bienes en vida de aquél.

No obstante lo anterior, el pacto sucesorio produce efectos de preeficacia en vida, ya que se consuma y consolida tras la muerte del instituyente.

En los pactos sucesorios se pueden constituir cargas, gravámenes y condiciones que debe cumplir el instituido so pena de revocación o resolución.

\section{II.2. Arraigo histórico de la institución}

Tradicionalmente, en el País Vasco (y por ende, en el Territorio Histórico de Vizcaya) siempre ha estado muy arraigada la libertad total a la hora de decidir el modo de elegir sucesor.

$\mathrm{Su}$ origen se encuentra en el hecho de que, antiguamente, era común entre una buena parte de los vizcaínos el poseer una explotación agrícola y/o ganadera familiar. Por ello, cuando los padres, ya mayores, veían que alguno de sus hijos o hijas poseían capacidad y cualidades suficientes para continuar la explotación de ese patrimonio familiar del cual vivían, era frecuente que optaran por hacerle sucesor de dicho patrimonio.

Dicho acto tenía lugar, generalmente, cuando dicho hijo o hija se hallaban próximos a contraer matrimonio, es decir, en las capitulaciones matrimoniales. Tanto los progenitores de ambos contrayentes como estos mismos concurrían al acto público donde los padres nombraban a su hijo/a sucesor/a de la explotación de la casa, reservándose para sí mismos el usufructo vitalicio de la mitad, con el fin de asegurarse un modo de vida hasta el final de sus días.

El otro contrayente (novio o novia), que también concurría con sus padres, aportaba una dote o bienes, con lo que los padres instituyentes podían ayudar a sus otros hijos y beneficiarles económicamente a pesar del apartamiento que inicialmente habían sufrido.

La razón de todo ello radica en mantener la unidad patrimonial de la explotación en una mano y que ésta continúe generando una riqueza de la que todos puedan beneficiarse, lo cual sería imposible si se realizara una división de aquella.

El instituyente generalmente imponía al instituido la carga de mantener y alimentar al resto de sus hermanos hasta que contrajeran matri- 
monio; e incluso a los propios instituyentes en caso de no establecer reserva del usufructo.

Merece destacar el trabajo de análisis de documentos públicos realizado al respecto por la profesora MONASTERIO ASPIRI, recogiendo y clasificando las distintas cláusulas y condiciones que se incorporaban en los pactos sucesorios en el derecho histórico vizcaíno. ${ }^{1}$

\section{II.3. Libertad de testar en el Código Civil}

La institución del pacto sucesorio aparece prohibida en el Código Civil, ya que éste se funda en la teoría romanista, según la cual no se puede aceptar y disponer de la herencia hasta después de la muerte.

Por contra, el Derecho civil vasco propugna la libertad de testar que defiende la tesis germanista.

Podríamos sintetizar los principios generales característicos del derecho sucesorio romano del siguiente modo:

-Principio de la sucesión universal, por la que el heredero adquiría los bienes hereditarios de una sola vez y en su conjunto.

— Responsabilidad ilimitada y personal; en virtud de esa consideración el heredero universal respondía de las deudas.

- Carácter familiar de la institución, de manera que la subrogación en los bienes hereditarios se hacía dentro de la estructura familiar.

Por contra, las legislaciones germánicas y medievales se basan en otros principios tan dispares que las características romanistas mencionadas le son extrañas. El derecho sucesorio germánico se funda en la consideración de la herencia como un conjunto de bienes de manera diferenciada, donde no se da la subrogación romanista en la persona del difunto, ni se sucede en la universalidad patrimonial respondiendo de las deudas. ${ }^{2}$

Existen posturas doctrinales defensoras de una u otra tesis. La romanista postula la seguridad del causante respecto del testamento realizado por aquél para después de su muerte, ya que el instituido por pacto sucesorio podría desear la muerte del instituyente tras conocer los bienes en los que iba a ser sucesor y a fin de que el pacto sucesorio tuviere eficacia plena. Pero estos mismos argumentos son usados $a$

\footnotetext{
1 MonASTERIO ASPIRI, Itziar, Los pactos sucesorios en el derecho vizcaíno, Universidad de Deusto-Diputación Foral de Bizkaia, Bilbao, 1994, págs. 211 y ss.

2 Castán Tobeñas José, Derecho Civil Español, Común y Foral. Tomo VI, Volumen I, Reus, Madrid, 1978, pág. 55.
} 
contrario sensu por los seguidores de la libertad de testar, al afirmar que el heredero puede desear y procurar la muerte del testador ante la posibilidad de una revocación unilateral del testamento.

Lo cierto es que en la confección del Código Civil imperó la tesis romanista, imponiéndose el testamento como única posibilidad de manifestar el causante su voluntad, aunque se admiten excepciones más o menos amplias. Así, el art. 1271 C.C. prohíbe cualquier tipo de pacto sobre la herencia futura salvo la remisión al art. 1056, el cual, aunque no regula ningún tipo de contrato, señala que habrá de estarse a los pactos que hubiere realizado el testador, preservándose siempre la legítima de los herederos forzosos.

En conclusión, la posición de nuestro ordenamiento jurídico respecto del pacto sucesorio es la de su prohibición, ya que en el art. 658 C.C. no se contempla como modo de deferir la sucesión la posibilidad del pacto sucesorio.

No obstante, a pesar de la regla expresada existen algunos preceptos que admiten la posibilidad de ciertos pactos sucesorios:

1. ${ }^{\circ}$. La promesa de mejorar y no mejorar de los arts. 826 y 827 del C.C. hecha en escritura pública o en capitulaciones matrimoniales, y la mejora realizada en un contrato oneroso celebrado con un tercero.

2. ${ }^{\circ}$. La donación de bienes futuros para caso de muerte, realizada entre consortes en capitulaciones matrimoniales. (art. 1341 C.C.)

En su momento también se podía incluir entre tales excepciones la sucesión contractual en la explotación agraria regulada en Ley 49/1981, de 24 de diciembre, del estatuto de la explotación familiar agraria y de los agricultores jóvenes, en cuyo artículo 16 se establecía la posibilidad de que el titular de una explotación «podrá convenir la sucesión en dicha titularidad con uno de sus legitimarios que reúna la cualidad de colaborador». Además, se establecía la posibilidad de otorgarse dicha sucesión a favor de un tercero que ostentara la cualidad de colaborador tanto si no había sucesores-colaboradores como si existiendo sucesores no concurriere la cualidad de colaboradores, en este último supuesto, con su consentimiento. En todo caso, debía mantenerse la cualidad del colaborador hasta la fecha del fallecimiento del causante, pues de otro modo podía revocarse. Y también podía resolverse por acuerdo entre las partes o por incumplimiento de las cargas y condiciones impuestas al colaborador-instituido.

No obstante, dicha regulación fue derogada por la Ley 19/1995, de 4 de julio, de Modernización de las Explotaciones Agrarias, en su Disposición Derogatoria Unica. 


\section{Regulación legal del pacto Sucesorio en Vizcaya}

\section{III.1. Regulación anterior: Ley de 30 de julio de 1959. La Compilación de Derecho Civil Foral de Vizcaya y Alava}

Como antecedente previo a la regulación actual, la Compilación, a diferencia - como ya se ha visto - del Código Civil, regulaba la sucesión y la libertad de designar sucesor en los bienes. Nótese la importancia de la tesis germanista al poder establecerse diferentes masas patrimoniales en las que designar uno o varios sucesores, tal y como se observa en los distintos preceptos:

«Art. 11. La designación de sucesor de bienes, sean o no troncales, deberá hacerse por testamento, capitulaciones matrimoniales, escritura de dote o donación.

Art. 12. La transmisión a título gratuito de un caserío con sus pertenecidos comprenderá, salvo disposición en contrario, el mobiliario, semovientes y aperos de labranza existentes en el mismo.»

Se establece en el Título Sexto - «Disposiciones comunes a la sucesión testada e intestada y a las donaciones» unos preceptos referidos a la totalidad de los bienes, obligaciones de reserva y a las disposiciones del donatario a favor sus hijos y descendientes, omitiendo cualquier posibilidad de disposición por parte del donante.

En la Ley 8. ${ }^{\text {a }}$, Título XVII, del Fuero, establecida como concordancia con el art. 39 de la Compilación, se recoge la posibilidad de venta de los bienes por parte del donante por incumplimiento de los alimentos que ha de prestarle el donatario, aunque realmente, y por la forma en que se dispone, más parece un llamamiento a que el donatario cumpla con las condiciones impuestas so pena de reversión.

«(...) y porque no se le acude con los tales alimentos como se debe, él hace llamamientos, y los pone en venta, diciendo: que él los vende para mantener el precio, y quien los quiere comprar: y acaece que por defraudar a su donatario, hace los tales llamamientos (aunque en iglesia) ocultamente. Por ende, por obviar semejantes fraudes, dijeron: Que establecían por ley, que en tal caso, el tal donatario sea requerido a que le dé los alimentos, y después de requerido, y mandado por el Juez, que cumpla el contrato, si no lo cumpliere, el tal donador dé tres llamamientos (...) y al tercer domingo, a quien los alimentos diere, se rematen los dichos bienes, y no en otra manera (...) y si no hubiere quien tome los bienes con el dicho cargo (dar alimentos), que los tales bienes queden, $\mathrm{y}$ tornen a dicho donador. 
III.2. Regulación Actual. Ley 3/1992, de 1 de junio, de Derecho Civil Foral del País Vasco

La actual regulación contempla claramente las distintas posibilidades de designar sucesor y además dedica un Capítulo a los pactos sucesorios.

Así, en el art. 27 se establecen los distintos instrumentos para llevar a cabo la designación sucesoria, y en el art. 74 se enuncian los modos y efectos que pueden tener:

«Art. 27. La designación de sucesor en bienes, sean o no troncales, tiene lugar por testamento, por ley, por pacto sucesorio, capitulaciones matrimoniales o escritura de donación.

Art. 74. Mediante capitulaciones matrimoniales, donación o pacto otorgado en escritura publica se puede disponer la sucesión en bienes de los otorgantes bien a titulo universal o particular, con las modalidades, reservas, sustituciones, cláusulas de reversión, cargas y obligaciones que se acuerden. Los otorgantes podrán asimismo ordenar la transmisión actual de todos los bienes presentes por parte de ellos o bien diferirla al momento de la muerte.»

Pero a efectos del presente trabajo interesa especialmente lo dispuesto en el art. 78, y concretamente el segundo párrafo, que va a ser el objeto de este estudio:

«La designación sucesoria con eficacia post mortem confiere al instituido la cualidad de sucesor en los bienes, que será inalienable e inembargable. Si la designación se hizo a favor del hijo que va a contraer matrimonio, éste podrá disponer de su derecho a título gratuito, por actos intervivos o mortis causa, a favor de sus hijos y descendientes.

\section{Si bien los instituyentes conservan la propiedad de los bienes, sólo podrán disponer de los mismos a título oneroso.»}

Los siguientes preceptos no guardan relación con el art. 78.2, es decir, con la posibilidad de disposición del instituyente a título oneroso, sino que regula la facultad de revocación por parte del instituyente, de resolución por las causas establecidas (cumplimiento de la condición resolutoria, fallecimiento del instituido sin descendencia o acuerdo de las partes en documento público) o reversión.

Así pues, en el caso de pacto sucesorio con eficacia post mortem el instituyente sigue teniendo la propiedad de los bienes y, aunque no pueda modificar el pacto realizado con el instituido sin que exista un acuerdo de voluntades, la Ley le permite disponer onerosamente de los bienes reflejados en la escritura pública. Y no se regulan límites a dichas disposiciones onerosas. 
Así, por poner un ejemplo, podríamos encontrarnos con que se ha dispuesto a favor del hijo/a un negocio concreto, que el instituido conoce y sabe explotar o bien se está preparando para ello, y el padre-instituyente podría cambiarlo por otro que le parezca más productivo, o incluso venderlo. Es evidente que ya no será sucesor en esa masa patrimonial que se le confirió en su momento; pero entonces, ¿qué reclamación o qué acciones legales podría entablar frente al instituyente que ha actuado conforme previene la Ley?

A este respecto la norma guarda silencio, ya que no existe un precepto que limite la capacidad de disposición del instituyente o que proteja o establezca las posibilidades de actuación del sucesor.

El art. 77, por contra, cuando se refiere al pacto sucesorio con eficacia de presente, en el que el instituido adquiere en vida la propiedad de los bienes, sí exige que «el citado acto de disposición o gravamen requerirá para su validez el consentimiento conjunto del instituyente e instituido»; pero la Ley silencia cualquier referencia en el supuesto objeto de este estudio. Podríamos pensar que si ambos, instituyente e instituido, forman una comunidad de bienes (art. 82), el sucesor tendrá conocimiento de las actuaciones del aquél, pero tal hecho no empece ni impide que las disposiciones onerosas que desee realizar el primero se lleven a cabo de la manera referida, pues la Ley no se lo impide ni le impone nada al respecto. Por lo tanto, el sucesor puede tener conocimiento de las disposiciones onerosas sin que, en principio, pueda hacer nada para evitarlas.

\section{La sucesión contractual en los demás Derechos civiles}

Los Pactos sucesorios, como ya se ha expresado, son un instrumento muy utilizado para designar al sucesor en los bienes, y dicha costumbre se ha ido recogiendo, compilando y legislando en los distintos derechos civiles y forales existentes en España.

Por ello, vamos a examinar brevemente cada uno de ellos, recogiendo el precepto, si existiere, que regula el objeto de este estudio: la facultad de disposición onerosa del instituyente en pactos post mortem y sus limitaciones.

\section{IV.1. Ley 15/1967, de 8 de abril, sobre Compilación del Derecho Civil de Aragón}

Con esta Ley, tal y como expresa su propio preámbulo, se ha pretendido recoger la tradicional vivencia y el peculiar entendimiento de la institución familiar aragonesa, actualizar el ordenamiento a las exi- 
gencias y cambios sociales y económicos. Se ha procurado un mayor rigor técnico-jurídico en su articulado, se han revisado preceptos que recogía el Apéndice anterior de 1925 y se ha realizado un acercamiento de este derecho al derecho civil general.

La institución del pacto sucesorio se regula en la Ley en el Título III «De la sucesión paccionada», arts. 99 a 109.

Siguiendo a RocA TRÍAs ${ }^{3}$ podemos clasificar los pactos sucesorios en Aragón como:

-Positivos, que determinan un sucesor o sucesores; y negativos, que permiten la renuncia.

- Matrimoniales, cuando se realizan en capitulaciones matrimoniales; y extramatrimoniales, cuando se llevan a cabo en escritura publica por personas capaces (mayores de edad) y se pueden beneficiar tanto parientes de los otorgantes como terceras personas.

En cuanto al carácter de las donaciones, se expresa en al art. 101 que las donaciones mortis causa tendrán el carácter de pacto sucesorio.

Pues bien, una vez sentado lo anterior, es en el art. 102 donde se regulan las «Facultades dispositivas del instituyente», expresando el precepto:

«1. En el nombramiento de heredero, pactado en consideración a la conservación del patrimonio familiar o de la casa, cuando el instituyente se reserve el "señorío mayor" u otras facultades análogas, se entenderá, salvo estipulación en contrario, que para disponer de los bienes inmuebles y de los comprendidos en el número 1 del art. $39^{4}$, es exigible el consentimiento del instituido que viniere cumpliendo las obligaciones y cargas impuestas en favor de la casa.»

2. No se requerirá, sin embargo, dicho consentimiento para disponer por donación, asignando a sus descendientes dotes o legítimas al haber y poder de la casa. Tampoco se necesita para hacer tales disposiciones en testamento.»

La razón de que se limiten las facultades del instituyente, como aquí se ha transcrito, se extraen del espíritu de la Ley recogido en el Preámbulo. Consta claramente la intención del legislador sobre este aspecto al dar una clara preeminencia exclusivamente familiar y consuetudinaria a los pactos sucesorios en evitación de que la «casa» o patri-

3 Roca Trías Encarna, Derecho civil, Derecho de sucesiones, coord. CaPILla RonceRO, F., Tirant lo Blanch, Valencia, 1999, pág. 298.

4 Art. 39.1. Presunción de muebles por sitios - A los efectos del artículo anterior se considerarán aportados al matrimonio adquiridos como sitios, salvo pacto en contrario:

1. ${ }^{\circ}$ Las explotaciones agrícolas, ganaderas. mercantiles, industriales, con cuanto elementos estén afectos a unas y otras (...). 
monio familiar se disgregue o pierda. Asimismo, en lo que se refiere a la libertad del instituyente recogida en el precepto anterior, y a falta de pacto al respecto, rige la misma limitación en cuanto a la enajenación de los inmuebles para garantizar, como ya se ha expresado, la permanencia de ese patrimonio y explotaciones familiares dentro de la familia durante generaciones.

\section{IV.2. Decreto Legislativo 79/1990, de 6 de septiembre, por el que se aprueba el Texto Refundido de la Compilación del Derecho Civil de las Islas Baleares}

En esta Ley, la sucesión contractual para la isla de Mallorca se establece a través de las donaciones universales. Esta institución, como dice ROCA TRÍAS ${ }^{5}$ "confiere al donatario la cualidad del heredero del donante, de una forma parecida a los heredamientos cumulativos del derecho catalán y a las donaciones propter nupcias del derecho navarro».

En cuanto a sus características, son las que se dan habitualmente en todas las legislaciones forales sobre sucesión contractual: negocio jurídico bilateral que ha de realizarse en escritura pública; y además, según la citada autora, es un negocio jurídico mixto, ya que tiene efectos por causa de muerte al ser irrevocable el nombramiento del heredero del donante, y al mismo tiempo tiene efectos inter vivos ya que le transmite los bienes presentes incluidos en la donación (art. 8).

Así pues, en el Libro I - «De las disposiciones aplicables a la isla de Mallorca», Título II - «De las sucesiones», no se regula el pacto sucesorio como tal, sino que es en el Capítulo «De las donaciones universales» donde se regulan éstas (art. 8 a 13) como donación de bienes presentes o futuros, pero nada dispone respecto a los pactos sucesorios a título singular ni en cuanto a las donaciones por causa de muerte, por lo que respecto a éstas regirá el Código Civil, de acuerdo con el art. 1.3 de la Compilación de las Islas Baleares en relación con el 13.2 del C.C.

En el Libro II - «De las disposiciones aplicables a la isla de Menorca», hace referencia expresa al Libro I, indicando: «Rige en la isla de Menorca lo dispuesto en el Libro I de esa Compilación, excepción hecha de los artículos 6 y 7 en lo referente a la donación universal de bienes presentes y futuros, del Capítulo II del Título II, de los artículos 50 y 51 y del Título III».

Es en las disposiciones aplicables a las islas de Ibiza y Formentera (art. 69), donde se establece la posibilidad de la sucesión por pacto su-

\footnotetext{
5 Roca TríAs, Encarna, op. cit., pág. 297.
} 
cesorio contenido en espolits (capítulos) con disposiciones mortis cau$s a$ a título singular, que se regirán por las reglas de los pactos sucesorios como la irrevocabilidad ( $a r t .74 .1 .^{\circ}$ ) y la de transmisibilidad, si el pacto sucesorio es con transmisión de presente, siendo en el Capítulo IV «De los pactos sucesorios» (arts. 72 a 77) donde se desarrollan.

En concreto, el precepto que aquí nos interesa es el art. 75:

«Los pactos sucesorios sin transmisión actual de bienes confieren únicamente la cualidad personalísima de heredero contractual, quedando revocados por premoriencia del instituido. El instituyente conservará hasta su muerte la propiedad de los bienes pero no podrá disponer de éstos en fraude del heredamiento.»

En este precepto también se limitan las facultades de disposición del instituyente en evitación de «fraude» del instituido; pero, a diferencia de la regulación legal de Aragón, en esta normativa no se hace mención, en cuanto a la limitación de facultades del instituyente, a la protección del patrimonio familiar, sino que lo que se preserva son los derechos del nombrado heredero. Se pretende así evitar que se desnaturalice el contenido del pacto en virtud de una libertad de disponer del instituyente fraudulenta en evitación del consentimiento que de otro modo necesitaría para ello (art. 74).

Al respecto, MonASTERIO ASPIRI ${ }^{6}$ sostiene que se presumirá la existencia de disposiciones en fraude del heredamiento cuando se cumplan los requisitos que a tal efecto se establecen en el art. 1297 del C.C.

\section{IV.3. Ley 1/1973, de 1 de marzo, por la que se aprueba la Compilación del Derecho Civil Foral de Navarra}

La compilación de Navarra, a diferencia de otras, pretende recoger su realidad social «como un fiel reflejo del Derecho civil realmente vigente en Navarra (...) y no como un simple registro de unas pocas particularidades jurídicas, por lo que recibe justamente la denominación de «Fuero Nuevo de Navarra» ${ }^{7} \gg$. Se ha prescindido de instituciones que estaban en desuso y se han incorporado otras consuetudinarias y de la práctica cotidiana que ofrecen soluciones actuales en consonancia y armonía con el sistema de derecho propio navarro.

Por lo que respecta a los pactos sucesorios, se admite el contrato sucesorio para diferir la sucesión por causa de muerte.

6 Monasterio Aspiri, Itziar, op. cit, pág. 267.

7 Exposición de motivos de la Ley 1/1973, de 1 de marzo, por la que se aprueba la Compilación del Derecho Civil Foral de Navarra. 
Las características de estos contratos llevan a calificarlo como un negocio jurídico personalísimo, que puede ser bilateral o plurilateral, ya que puede contener estipulaciones para los dos contratantes o sólo para uno de ellos e incluso para un tercero, y es un acto formal (escritura pública) e irrevocable que otorga un título mortis causa.

De nuevo siguiendo a RoCA TRÍAs ${ }^{8}$, la compilación de Navarra prevé dos clases de pactos sucesorios: los generales, donde se pueden establecer, modificar, extinguir y renunciar derechos de sucesión mortis causa de una herencia o parte de ella; y las donaciones propter nuptias que suponen una donación de bienes presentes y futuros por la que el donatario adquiere los bienes que se le confieren de presente y sucede como heredero (Ley 115).

Los pactos o contratos sucesorios se regulan en el Título IV, Leyes 172 a 183, siendo en el Capítulo II - «Disposiciones especiales sobre los pactos de sucesión», donde, respecto a los efectos de estos pactos, expresa la Ley 179:

«Ley 179: Efectos. Los pactos sucesorios sin transmisión actual de bienes confieren únicamente la cualidad de heredero contractual, que será inalienable e inembargable. El instituyente conservará hasta su muerte la propiedad de los bienes, pero no podrá disponer de éstos a título lucrativo sin el consentimiento del instituido. En los pactos sucesorios con transmisión actual de bienes, el instituyente podrá reservarse la facultad de disponer por cualquier título o sólo por título oneroso. Los actos de disposición no reservados serán nulos sin el consentimiento expreso del instituido. Las acciones de nulidad sólo podrán ejercitarlas el instituido y sus causahabientes, incluso en vida del instituyente.»

Como se deduce del texto transcrito, en la legislación civil navarra ha existido una preocupación sobre la posición del sucesor frente a la libertad de disposición del instituyente, garantizando sus derechos pactados y en evitación de que se vean minorados o defraudados sus intereses.

\section{IV.4. Ley 40/1991, de 30 de diciembre. Código de Sucesiones por causa de muerte en el Derecho Civil de Cataluña}

Cataluña ha sido el territorio donde más legislación civil escrita ha existido, ya que tradicional e históricamente se ha estudiado y legislado sobre sus instituciones, teniendo, por tanto, ley escrita desde antiguo.

8 Roca Trías, Encarna, op. cit., pág. 299. 
La que ahora examinamos - como se ve, muy reciente en el tiempo- es un Anexo que tiene su origen en la necesidad de adaptar la Compilación anterior a nuestra Constitución.

Se establecen en el art. 3 las formas de deferir la sucesión, distinguiendo tres: los heredamientos, el testamento y la Ley.

Se denomina en derecho civil de Cataluña heredamiento a la institución contractual de heredero, que habrá de otorgarse necesariamente en capitulaciones matrimoniales, personalmente o mediante poder especial (art. 67), distinguiéndose diversas clases: heredamiento a favor de los contrayentes, a favor de los hijos de los contrayentes y heredamientos mutuales. Aquí, dado el objeto del estudio, nos vamos a centrar en el primero.

En el heredamiento a favor de los contrayentes, los padres, futuros causantes, disponen de sus bienes a favor de su hijo con ocasión de su matrimonio, otorgándole la cualidad de heredero (existiendo distintas clases: puros, preventivos y prelativo).

«Art. 79. El heredamiento simple confiere únicamente la calidad de heredero contractual, que será inalienable e inembargable.

El heredante conservará hasta el fallecimiento la propiedad de sus bienes, pero no podrá disponer de ellos a título lucrativo sino para hacer regalos módicos y liberalidades de uso o para legar lo que en el heredamiento se hubiera reservado para testar aparte de la facultad de dotar y acomodar a los hijos y de disponer a favor de éstos en los términos previstos en el art. 81.

Los actos de disposición a título oneroso que de sus bienes el heredante realice serán anulables cuando sean otorgados en fraude del heredamiento, salvo que el adquirente sea extraño al fraude. Esta acción y la de simulación, en su caso, sólo podrá ejercitarla el heredero o quien lo sea de éste, incluso en vida del heredante.»

Se hace patente que en esta legislación ha existido una preocupación real sobre este problema regulándolo del modo que se hace, comprendiendo la realidad social y que el hecho de que estos contratos se hagan entre familiares y parientes no empece la existencia de situaciones fraudulentas.

\section{IV.5. Ley 147/1963 de 2 de diciembre, sobre Compilación del Derecho Civil de Galicia}

La Compilación gallega recoge la mejora de labrar y poseer como medio jurídico para la conservación indivisa del patrimonio en sus arts. 84 a 87, conferido entre el causante y uno de sus descendientes al que se le atribuye una explotación agrícola o establecimiento fabril o comercial. 
Según la profesora MonaSTERIO ${ }^{9}$ «este derecho puede conferirse mediante actos inter vivos o mortis causa, mejorando al hijo elegido y en tal concepto confiriéndole la titularidad sucesoria de la explotación agrícola familiar».

Nada se expresa respecto a la eficacia de presente o post mortem del derecho, ni se pronuncia sobre las facultades que pueda tener el ascendiente sobre los bienes de que dispone. No es un pacto sucesorio como tal, aunque recoge la inquietud porque el patrimonio familiar tradicional permanezca unido e indivisible.

\section{IV.6. Conclusión}

De todo lo hasta aquí expuesto, observamos que las legislaciones que recogen la posibilidad del pacto sucesorio y de la libertad de testar hacen referencia de manera expresa a limitaciones que se imponen al instituyente para disponer de sus bienes en sucesión contractual de eficacia post mortem, a diferencia del Derecho civil vasco que lo omite. Pero la protección al sucesor en los bienes y las limitaciones que se le imponen al instituyente o heredante son diferentes, y podríamos agruparlas en dos bloques:

- Las que se limitan a la mención de la necesidad del consentimiento del sucesor (Aragón y Navarra).

- Las que van más allá, refiriéndose a la posibilidad de la existencia de un fraude en perjuicio del instituido por las disposiciones onerosas del heredante (Baleares y Cataluña). En este caso, la normativa catalana corona además su regulación al referirse a las distintas acciones que puede ejercer el sucesor en evitación del posible fraude que le impida el disfrute de los bienes: anulabilidad y simulación del contrato otorgado por el heredante con otro tercero.

Llama la atención que estos dos niveles que hemos llamado de protección se den en territorios que tienen proximidad geográfica entre sí, así como costumbres y, en su caso, un idioma afín.

\section{Análisis de la cuestión en el Derecho civil común}

Ya se han examinado las diferentes soluciones que las regulaciones civiles forales dan al problema planteado. Como quiera que la regulación de la legislación vasca sobre las limitaciones a la facultad de dis-

9 Monasterio AzPIRI, Itziar, op. cit., pág. 425. 
posición onerosa del instituyente en pactos sucesorios post mortem es inexistente, deberemos acudir al derecho común en busca de soluciones adecuadas, basándonos en las instituciones más semejantes.

\section{V.1. El Legado}

\section{V.1.1. El LEgado FRENTE Al PACTO SUCESORIO}

Para el estudio de este apartado nos vamos a fijar en el legado de cosa cierta, ya que es el que tiene relación con el nombramiento de sucesor en los bienes por pacto sucesorio que estamos analizando y respecto del precepto del Código Civil que luego se examinará.

La equiparación del pacto sucesorio al legado se ha establecido por distintos autores. Así, Roca SASTRE-MunCUNILL ${ }^{10}$, cuando se refiere a las donaciones mortis causa, indica que la doctrina científica española mayoritaria (siguen a esta corriente Roca SASTRE, FuenMayor, PARRA, PORRAS) entiende que este tipo de donación «es una institución suprimida que hay que refundir en el legado», ya que el Código Civil, aunque reconoce la existencia de la donación por causa de muerte, a efectos de simplificación jurídica «dado que en el fondo equivale a un legado, no se permite que se emplee dicha figura jurídica, de suerte que quien desee otorgarla deberá hacerlo en testamento». No olvidemos que la sucesión en bienes por pacto sucesorio se puede realizar a través de diversos instrumentos, siendo uno de ellos la donación.

La jurisprudencia del Tribunal Supremo sobre donaciones por causa de muerte ha seguido esta posición mayoritaria de supresión (Sentencias de 8-2-1905, 24-4-1909, 4-11-1926, 8-7-1943, 23-3-1948, 19-6-1956, 28-10-1965, 7-1-1975 y 28-4-1975).

Podríamos decir que tanto el instituido por causa de muerte como el legatario tienen una expectativa de su derecho, puesto que han de esperar a la muerte del heredante para comprobar la realidad de lo que se les ha conferido.

Aunque existen claras diferencias entre ambas instituciones - ya que el pacto es irrevocable y el testamento es revocable por naturaleza, siendo a priori situaciones diferentes las de uno y otro- no debemos perder de vista que, en cuanto al objeto de análisis de este estudio, estas diferencias no son irreductibles, al menos como hipótesis de trabajo, ya que el instituyente puede realizar disposiciones onerosas respecto del bien objeto del pacto tal y como hemos referido, al igual que el tes-

10 Roca Sastre-Muncunill, Luís, Derecho de Sucesiones, Tomo III, Bosch, Barcelona, 1989, pág. 137, Nota 284. 
tador puede modificar el legado. Ambos consolidan su derecho a la muerte del testador siendo propietarios de los bienes dejados o legados desde el óbito.

Siguiendo a CASTÁN TOBEÑAS ${ }^{11}$, el legatario, con carácter general, puede ejercer las siguientes acciones:

1) Acción personal para pedir su legado, que los romanos llamaban ex testamento. Frente a ella el instituido podrá ejercitar la correspondiente al art. 1124 del C.C. en cumplimiento del contrato.

2) Siendo el legado de cosa determinada, supuesto del que hemos partido por similitud a la figura objeto de comparación, el legatario, al ser dueño de ella desde la muerte del testador, puede ejercitar la acción reivindicatoria contra quien la tenga. En principio también entendemos que le corresponde al instituido con carácter general, salvo en el caso del supuesto específico del precepto que analizamos.

3) Si además no hay herederos ni albaceas y nadie posee los bienes como dueño, puede inscribir su legado en el registro de la propiedad y posteriormente solicitar judicialmente la entrega de la posesión o interponer un interdicto de adquirir.

Y lo mismo cabe señalar respecto al instituido, salvo el caso del art. 78.2 de la Ley 3/1992 de Derecho Civil Foral del País Vasco.

El instituido, como indica CELAYA IBARRA ${ }^{12}$, «tiene un derecho expectante sobre el patrimonio del instituyente, pero este derecho quedará determinado en el momento de la muerte del causante» y para garantizar su derecho la Ley 3/1992 le impide disponer de sus bienes a título gratuito pero nada dice sobre las disposiciones a título oneroso.

Según Monasterio ${ }^{13}$, como quiera que las disposiciones que se permiten al instituyente son a «título oneroso « por efecto de la subrogación real, no cabe que quede burlada la expectativa del instituido.

Ciertamente, el sucesor a la muerte del instituyente percibirá, en principio y salvo lo que se diga con posterioridad, lo que haya integrado el heredante como nuevo patrimonio en sustitución de la masa de la que dispuso; pero, aunque teóricamente esto sea así, plantea, al menos a quien esto escribe, una serie de problemas que también se dan en el legado (art. 869 C.C.): enajenación y transformación del bien.

11 Castán Tobeñas, José, op. cit., pág. 305.

12 Celaya Ibarra, Adrián, Comentarios al Código Civil y Compilaciones Forales, coord. Albadalejo García, Manuel, Revista de Derecho Privado, Tomo XXVI, Edersa, Madrid, 1978, pág. 305.

13 Monasterio AzPIRI, Itziar, op. cit., pág. 207. 
Supongamos, por ejemplo, que el ascendiente intuye que ese negocio de tintorería del que va a hacer sucesor al instituido (o taller de siderometalurgia, tienda de ultramarinos, pequeño supermercado, etc.) se encuentra más atrasado que otros de la zona o en decadencia, y para cuando el instituido acabe sus estudios, alcance la edad para regentarlo, o la preparación necesaria, va a ser demasiado tarde para actualizarlo. ¿Qué ocurriría entonces? Veamos dos posibilidades que, en la práctica, podrían plantearse:

-Primera posibilidad (transformación): el instituyente, debido al avance social, observa que otro negocio puede ser más provechoso, cambiando la masa patrimonial que en principio había conferido al instituido (léase, por ejemplo, sustitución de la tienda de ultramarinos por un cyber-café, una taberna irlandesa o una parafarmacia).

- Segunda posibilidad (enajenación): una entidad bancaria o una cadena de alimentación le ofrece al instituyente una cantidad de dinero insospechada por el local para instalar allí una sucursal de su actividad.

En ambos casos no estamos planteando que exista mala fe ni fraude por parte de ese ascendiente, sino que lo hace por entender que pueda ser la mejor solución en un momento concreto, o por política comercial, si se prefiere.

Es evidente que el instituido se va a encontrar con algo muy diferente de lo que se le confirió a través de un pacto que aceptó y para lo que posiblemente haya estado preparándose durante años, o sea un negocio que le guste y del que entienda su funcionamiento.

La situación descrita tiene similitud con lo contemplado en el art. 869 C.C., por lo que para realizar este análisis nos vamos a centrar y seguir el brillante artículo de MANUEl Albaladejo ${ }^{14}$ sobre el citado precepto.

\section{V.1.2. LA TRANSFORMACIÓN Y LA ENAJENACIÓN EN LA INSTITUCIÓN DEL LEGADO}

Dice así el art. 869:

«El legado quedará sin efecto:

$\left.1^{\circ}{ }^{\circ}\right)$ Si el testador transforma la cosa legada, de modo que no conserve ni la forma ni la denominación que tenía.

14 Albaladejo García, Manuel, El artículo 869 del Código Civil, Revista de Derecho Privado. 1980, págs. 1079 y ss. 
$2^{\circ}{ }^{\circ}$ Si el testador enajena, por cualquier título o causa, la cosa legada o parte de ella, entendiéndose en este último caso que el legado queda sólo sin efecto respecto a la parte enajenada. Si después de la enajenación volviere la cosa al dominio del testador, aunque sea por la nulidad del contrato, no tendrá después de este hecho fuerza el legado, salvo el caso en que la readquisición se verifique por pacto de retroventa.

3. ${ }^{\circ}$ Si la cosa legada perece del todo viviendo el testador, o después de su muerte sin culpa del heredero. Sin embargo, el obligado a pagar el legado responderá por evicción, si la cosa legada no hubiere sido determinada en especie, según lo dispuesto en el art. 860.»

Del artículo transcrito observamos que el primer párrafo se refiere a la imposibilidad de transformación del legado y el segundo a la enajenación (prescindiremos del tercero, aunque muy interesante, por no tener relación con el paralelismo que pretendemos establecer con el art. 78.2 de la Ley 3/1992).

AlBALADEJO desentraña y analiza las cuestiones que surgen del citado precepto distinguiendo los diferentes supuestos que se plasman en sus párrafos $1 .^{\circ}$ y $2 .^{\circ}$ : el problema de la transformación del legado y el de la enajenación.

\section{V.1.2.1. La transformación}

La transformación del legado de manera que no conserve ni la forma ni la denominación que tenía producirá su ineficacia.

No es transformación el mero embellecimiento de la cosa o que la finca se trasforme de secano a regadío, como dice MARÍn CASTÁN ${ }^{15}$. Lo importante es que se produzca un cambio sustancial, de manera que ese cambio no pueda considerarse un plus, sino un aliud.

Ahora bien, para que esto ocurra así es imprescindible, como luego veremos, que se deba a la voluntad del testador; e, incluso adelantándonos, debemos decir que tal voluntad ha de ser real.

Así, Albaladejo distingue varios supuestos que agrupamos de la siguiente manera:

a) Transformación por voluntad del testador.

El precepto se inicia expresando «si el testador transforma (...)». Es evidente que es necesaria una voluntad del testador de variar la cosa objeto de legado. Al ser esto así el legado es inefi-

15 Marín CASTÁn, Francisco, op. cit., pág. 40. 
caz, y el legatario no podría reclamarlo por ser cosa distinta de la legada que era ex re certa. Lo importante de esta ineficacia no es la transformación de la cosa, sino la voluntad del testador de que así sea, que es lo que torna realmente ineficaz el legado.

Por eso, aunque el legado retorne a su estado anterior no le devuelve su eficacia, ya que aquél se perdió por la voluntad de transformación de quien lo concedió.

Si el testador desea que, aún existiendo transformación, el legado se mantenga, debe hacerlo constar así en testamento, y obviamente antes de que ocurra la transformación. Por el contrario, si ésta ya ha tenido lugar deberá hacer un legado de cosa nueva.

También deberá legar de nuevo cuando la transformación vuelva a su estado primitivo, y manifestar así su voluntad real.

b) Transformación total y transformación parcial.

Como hemos visto, el precepto exige para su ineficacia que el legado no conserve ni la forma ni la denominación que poseía; pero en casos de transformación parcial habrá que entender revocada la parte del legado transformada y mantenerse la que quedó intacta.

c) Transformación del legado no realizada por el testador.

En este caso nos encontramos ante supuestos de modificación de la cosa por la vía de hecho, sin que haya concurrido la voluntad del testador ni que haya deseado la transformación con la que se encuentra.

¿Sería ineficaz el legado? Entendemos, al igual que el autor, que la respuesta ha de ser negativa, ya que no ha sido la voluntad del testador quien ha determinado la transformación de la cosa. El no lo ha querido. Por lo que, tanto siguiendo la literalidad del precepto («si el testador transforma...»), al igual que lo apuntado anteriormente sobre la determinación de la voluntad del testador para la ineficacia del legado, habremos de entender que éste se mantiene en la cosa transformada.

Podríamos pensar en una expropiación con permuta de tierras o en una concentración parcelaria en la que se cambia un bien por otro/s. Parece lógico pensar que el legado se mantenga, pues el testador no ha querido otra cosa diferente.

Del mismo modo ha de considerarse si la cosa así transformada, por tercero o por azar, retorna a su estado primitivo antes del fallecimiento del testador, pues la voluntad de éste ha quedado, tal y como hemos referido, al margen de cualquier cambio. 


\section{V.1.2.2. La enajenación}

Según MARín CASTÁn, «por enajenación debe entenderse todo acto de disposición que suponga una pérdida de dominio de la cosa» ${ }^{16}$. MANRESA, por su parte entendía que también existía enajenación cuando se constituía una servidumbre, un usufructo o una hipoteca sobre la cosa objeto de legado; frente a lo cual ALBALADEJo entiende, con acierto, que esos no son casos de enajenación del legado, sino de la aplicación de los arts. 867 y 868 C.C.

En esta parte, y como quiera que se mantiene como criterio de ineficacia del legado la voluntad del testador, las soluciones a los distintos supuestos van a ser similares, si no idénticas, a las referidas respecto de la transformación en muchos de ellos.

a) Enajenación por voluntad del testador.

Al igual que respecto de la transformación, para que la enajenación haga ineficaz el legado debe hacerse por voluntad del testador. Lo determinante para dicha ineficacia no es que la cosa legada ya no se encuentre en manos de un tercero, sino que se ha manifestado la voluntad del testador al desprenderse de ella.

El propio precepto expresa «si el testador enajenare $(\ldots)$ », plasmando la voluntad que debe de existir en tal acto de disposición.

Destacar, que si la enajenación se ha realizado pero no consumado (falta la traditio) no por ello se mantiene el legado, ya que lo determinante es la voluntad del testador manifestada en la decisión de realizar tal enajenación. Ni tampoco en los casos en que la enajenación sea nula y vuelva el bien a la esfera patrimonial del testador, puesto que ya se ha manifestado su voluntad de enajenar.

Se mantiene el legado en los casos de enajenación con pacto de retroventa (reservándose el testador el derecho a adquirir) y también en aquellos supuestos en que se indique en el propio testamento la voluntad de que el legado permanezca a pesar de la enajenación.

Respecto de las enajenaciones inválidas, el criterio preeminente, según Albaladejo, y a tenor de todo lo expuesto hasta ahora, es que habrá de estarse en tales supuestos a la voluntad del testador en cuanto a tal disposición.

16 Marín Castán, Francisco, ibidem. 
b) Enajenación total y enajenación parcial.

No todo acto de enajenación anula el legado. Si es total, se ha manifestado la voluntad del testador respecto de la cosa que la hará ineficaz; pero si sólo se ha enajenado una parte, el legado se mantiene respecto a la no enajenada.

c) Enajenación del legado no realizada por el testador.

En este caso, como en la transformación, nos encontramos con situaciones en las que el legado se pierde por causas distintas de lo querido por el testador. El Tribunal Supremo entiende en estos casos que el legado mantiene su eficacia en supuestos de concentración parcelaria (se mantiene en las fincas de reemplazo), permuta (en la nueva que se adjudica) o expropiación forzosa (se mantiene en el importe del justiprecio).

Cuestión distinta sería si se hubiera dispuesto del legado por acreedores del testador y se subastara la cosa, en cuyo caso el legado se mantendría porque, siguiendo el criterio expuesto, el testador no deseó lo contrario. Otra cosa es que el legatario no perciba nada por su legado, considerándose por ALBALADEJO que se mantiene como de cosa ajena, en contra del resto de la doctrina, que entiende que existe imposibilidad de cumplir el legado.

\section{V.2. Confrontación de la teoría de la transformación y enajenación del legatario y legado con las facultades de disposición del instituyente en el pacto sucesorio (art. 78.2 Ley 3/1992)}

En este apartado vamos a intentar concordar lo que se ha analizado sobre el testador y el legatario respecto del instituyente y el instituido en el pacto sucesorio con eficacia post mortem en lo que respecta al segundo inciso del art. 78 de la Ley 3/1992, a fin de comprobar si tales figuras se integran en los supuestos objeto de análisis o si, por el contrario, no admiten tal equiparación por tener diferente naturaleza.

\section{V.2.1. LAS FACULTADES DE DISPOSICIÓN DEL INSTITUYENTE}

En el análisis realizado en cuanto a la figura referida del Código Civil, se ha perfilado como determinante de la ineficacia o mantenimiento del legado la voluntad del testador. Esta era la única razón a la hora de analizar los distintos supuestos expuestos tanto de la transformación como de la enajenación. 
En el caso que nos ocupa (facultad de disposiciones onerosas por el instituyente) partimos de la inexistencia de un precepto similar que nos ofrezca una pauta a examinar, limitándose su regulación a dos líneas que nada refieren al respecto:

\section{«Si bien los instituyentes conservan la propiedad de los bienes, sólo podrán disponer de los mismos a título oneroso.»}

De la mera lectura de esta norma se desprende que se deja a la voluntad del instituyente la posibilidad de disposición del bien conferido por pacto. Ahora bien, ¿dicha voluntad así manifestada supone una intención de declarar la ineficacia del pacto, como ocurre en el legado?

El pacto sucesorio, a diferencia del testamento, no se puede revocar unilateralmente por el instituyente; para ello es necesario el consentimiento del sucesor «y por las causas que hayan establecido las partes» (art. 75 de la Ley 3/1992).

Por lo tanto, ¿podemos considerar en el pacto sucesorio la voluntad del instituyente respecto a las facultades dispositivas que la ley le confiere como determinante para determinar la ineficacia del pacto?

\section{V.2.2. Voluntad DEL INSTITUYENTE COMO MANIFESTACIÓN TÁCITA DE REVOCACIÓN E INEFICACIA DEL PACTO SUCESORIO}

\section{V.2.2.1. La transformación}

Si partimos como premisa de una respuesta afirmativa, y siguiendo los mismos criterios que para el legado, nos encontramos con que la transformación del negocio familiar (supermercado, tintorería, caserío...) en otro (taberna irlandesa, cyber-café, agroturismo...) supondría una revocación tácita del pacto, por lo que el instituido perdería su condición de sucesor en ese bien, así como sus expectativas de explotar tal negocio familiar.

Para que se mantuviese vigente se debería verificar otro pacto, designándole sucesor en ese nuevo bien. Podría continuar vigente aquel primer pacto sucesorio si en él se indicara expresamente, y antes de que tuviera lugar la transformación, que se mantiene aunque la masa patrimonial se vea modificada en su forma y denominación, ya que de otro modo perdería su condición. Igualmente, quedaría ineficaz el pacto si la transformación ya hubiera tenido lugar o si el bien transformado retornara a su forma original, ya que la voluntad del instituyente se habría manifestado mediante la transformación realizada, por lo que sería necesario verificar un nuevo pacto. 
Si la transformación fuera parcial (por ejemplo, el caserío transforma sólo su mitad en un establecimiento de agroturismo), permanecería el pacto en la parte del bien no transformada.

Respecto a transformaciones operadas sin la voluntad del instituyente (por ejemplo, una concentración parcelaria o una permuta administrativa), el pacto se mantendría vigente, siendo el instituido sucesor en las nuevas tierras concedidas.

\section{V.2.2.2. La enajenación}

En lo que se refiere a la enajenación, y tal como veíamos respecto del legado, su aplicación en el pacto sucesorio va a ser similar a lo obtenido en la transformación. La voluntad del heredante permanece y es determinante respecto de la validez de la institución que se analiza.

Así, si se enajenara el bien objeto de pacto se deduciría, quizás de manera más clara que respecto a la transformación, la voluntad del instituyente de revocar el pacto, ya que dicho bien sale de su esfera patrimonial aunque se integre en su lugar el importe dinerario percibido a cambio. Puede entenderse que es una manera más radical, pero más concluyente, de manifestar al instituido que no se le desea como sucesor en el bien y que se prefiere desprenderse de éste antes de que acabe en su patrimonio.

Por ello, esta voluntad revocatoria se mantendría para supuestos en que no se hubiera perfeccionado la enajenación del bien; o en el supuesto de nulidad de la enajenación; o de que, realizada ésta, retornara dicho bien a la esfera patrimonial del instituyente. Sólo se mantendría la validez tras la enajenación cuando expresamente así se indicara en el pacto sucesorio o en supuestos de pacto con retroventa.

En casos de invalidez habría de estarse a la voluntad del instituyente, como se dijo para el legado.

En supuestos de enajenación parcial del bien, el pacto estaría vigente en la parte no enajenada. Por ejemplo: se vende la mitad del caserío o del local de supermercado, quedando en ambos casos reducido el bien asignado al sucesor.

De igual modo ocurriría en supuestos de enajenación no deseada por el instituyente: se mantendría el pacto al no haberse manifestado la voluntad de éste. Piénsese en la subasta del bien para pago de acreedores, o una expropiación del caserío y sus pertenecidos: recibiría el sucesor el sobrante si lo hubiere en el primer caso, y el justiprecio en el segundo. 


\section{V.2.2.3. Acciones del instituido}

\section{a) Transformación y/o enajenación total}

Ante estos supuestos en los que se ha admitido para el análisis que la voluntad del instituyente del art. 78.2 es determinante e implica una revocación del pacto sucesorio, el instituido carecería, en principio, de acciones judiciales contra el instituyente, pues nos encontraríamos con que esas disposiciones onerosas estarían amparadas por lo ya explicado. No obstante lo cual, entendemos que eso no es del todo cierto, ya que la expectativa del sucesor en ese bien, que posteriormente se frustra por las acciones del heredante - y que en muchos casos le ha supuesto invertir años de preparación y de adquirir una experiencia para después explotar esa masa patrimonial concedida, o de rechazar en su caso otros trabajos bien remunerados por cumplir con el pacto otorgado y que, además, como en las capitulaciones matrimoniales, puede afectar al matrimonio - no puede quedarse sin resarcimiento alguno a favor del instituido.

Así pues, si permitimos la revocación unilateral del pacto sucesorio podríamos entender que cabría aplicar, en todo caso, la posibilidad que ofrece el art. 1902 del Código Civil respecto de la culpa extracontractual:

\section{«El que por acción u omisión causa daño a otro, interviniendo culpa o negligencia, esta obligado a reparar el daño causado.»}

El sucesor tendría que demostrar el daño que esa disposición del bien le ha causado (daños morales, perjuicios económicos...) con la dificultad de prueba que en muchos casos conlleva.

De igual manera habría que aceptar la posibilidad de ejercer una acción de enriquecimiento injusto si hubieran realizado inversiones para mejorar el bien, de las cuales se haya beneficiado el instituyente.

\section{b) Transformación y/o enajenación parcial o sin concurrencia de} la voluntad del instituyente

En estos supuestos el sucesor recibe parte del bien que le ha sido asignado, o el substitutivo del bien o dinero en caso de que no lo haya deseado el heredante.

Aceptando la transposición de las reflexiones realizadas para el legado, el sucesor quedaría «pagado» con lo que a cambio se le entregue, aunque puedan darse supuestos en que se haya minorado o transformado tanto el patrimonio inicialmente otorgado que pueda no interesarle.

En este caso entendemos que carecería de la acción del 1902 C.C., ya que la modificación o minoración patrimonial del bien estaría legal- 
mente realizada y admitida sin implicar fraude alguno, sino tan sólo una voluntad modificadora de lo pretendido inicialmente y plasmado en el pacto sucesorio.

\section{Conclusiones}

\section{VI.1. Análisis de los supuestos desde la propia institución del pacto sucesorio. Espíritu del legislador}

Ya se ha expresado en apartados anteriores las diferencias entre el legado y el pacto sucesorio. El primero es un instrumento de manifestación de la última voluntad del causante, unilateral, donde no concurre ninguna anuencia de voluntades y por ello perfectamente modificable tantas veces como quiera el testador para elegir a quien quiere mejorar, legar con carácter preferente a otros, según evolucione su vida y la de los posibles herederos y legatarios. Por ello y porque, como hemos dicho, la voluntad del causante es la determinante en las modificaciones testamentarias, existen preceptos como los analizados apartados 1 y 2 del art. 869 C.C. donde se regulan las diferentes situaciones que revocan los legados en virtud de las manifestaciones de voluntad del testador sobre aquéllos.

Pero el pacto sucesorio es una institución muy diferente. Es un contrato, un acuerdo de voluntades entre el instituyente y el que ha de ser designado en la sucesión de determinados bienes. Ambos suscriben el documento público en el cual se plasma dicho pacto y establecen, en su caso, las cláusulas y cargas que deba cumplir el instituido so pena de revocación o resolución del contrato. Así mismo, el pacto sucesorio prevalece sobre cualquier disposición testamentaria anterior respecto del bien objeto de pacto (art. 75 Ley 3/1992), por lo que el legislador está confiriendo mayor valor al acuerdo de voluntades alcanzado por las partes en el pacto que a la decisión unilateral del instituyente en un testamento anterior.

La vigente Ley de Derecho Civil Foral del País Vasco manifiesta en todas sus disposiciones sobre esta institución la intención de que el pacto sucesorio sea un medio que garantice y permita una mejor elección en el nombramiento del sucesor en los bienes. Estamos hablando de relaciones familiares donde la preocupación es que aquellas masas patrimoniales queden en las mejores manos, unificadas para la perdurabilidad del patrimonio.

También regula dicha Ley las formas de transmisión de estos bienes (con eficacia de presente o post mortem), siendo interesante desta- 
car que cuando el pacto tiene eficacia de presente, la Ley exige para disposiciones gravosas la concurrencia del consentimiento entre instituyente e instituido.

Ello nos debe llevar a concluir que de igual modo ha de operarse en aquellos que tengan eficacia post mortem. Lo lógico es que el instituyente solicite el consentimiento, fehaciente o verbalmente, al instituido para disponer onerosamente de dichos bienes y que ambos lleguen a la decisión de realizar tal disposición.

Por ello, entendemos que no es aplicable al caso que nos ocupa lo examinado respecto del legado, aún cuando puedan existir también transformaciones o enajenaciones de los bienes objeto del pacto sucesorio, ya que la naturaleza de la institución y el espíritu del legislador, que a su vez ha pretendido recoger en el texto de la ley, precipitadamente o no, la tradición de estas instituciones, nos pone de relieve que son diferentes, no pudiendo dejar al arbitrio de una de las partes (el instituyente) tal variación del contenido del pacto que fue aceptado en su momento por el sucesor.

\section{VI.2. Análisis de la cuestión en relación con la regulación del contrato en el Código Civil}

La pauta para analizar la situación del instituido respecto de las disposiciones onerosas que realice el instituyente según el art. 78.2 de la Ley civil del País Vasco nos la dan los derechos civiles forales reseñados en el apartado IV de este estudio.

Unas legislaciones recogen la necesidad del consentimiento del sucesor cuando el pacto se realiza para la conservación del patrimonio familiar (Aragón) y para actos no reservados por el instituyente (Navarra), y en otras se alude expresamente a la posibilidad de disposiciones onerosas en fraude del instituido y a las acciones de nulidad y simulación.

No se puede afirmar tajantemente que, como las disposiciones que la ley permite realizar al instituyente son onerosas, por subrogación quedan salvados los derechos del instituido en virtud del pacto. Pensemos, por ejemplo, en el heredante que realiza una disposición onerosa consistente en una compraventa del bien objeto de pacto, y que por desavenencias posteriores con el instituido decide venderlo por un precio inferior al real (sin que sea muy exagerado). En este caso, aunque el sucesor se subrogue en el capital objeto de venta éste es claramente inferior al real, con lo que se ha mermado el patrimonio concedido en origen.

Pero además, aunque se subrogue en el capital y no haya fraude en la disposición, el pacto original queda transformado en una cantidad de 
dinero. ¿Cómo se garantiza su valor, si el pacto tiene efectos post mortem?

No es esta una cuestión baladí ya que:

a) Si en el pacto con tal eficacia no se ha acordado una comunidad de vida entre ambos pactantes o se ha previsto el usufructo de la mitad del bien, el instituyente podría disponer de ese dinero para su supervivencia, con lo que, según su longevidad, puede minorar e incluso anular los derechos del instituido (que, aunque expectantes, son ciertos) y el pacto original.

b) Aunque el heredante tenga otros bienes de los que vivir, ¿debe guardar celosamente ese capital obtenido por la compraventa para que no se minore? Entonces nos encontraríamos con que, al cabo de los años, ese dinero no va a representar en absoluto el valor del patrimonio del que se dispuso.

Por otro lado, ¿qué ocurriría si el instituyente realizara una disposición onerosa respecto de otro de sus descendientes? ¿Podríamos aquí entender una voluntad de revocar el pacto aunque el instituido se subrogue en el precio? Y si la disposición se realiza a favor del propio instituido que adquiere la propiedad del bien objeto del pacto por medio de compraventa y precio cierto, ¿podría reclamar post mortem?

La cuestión no es sencilla, y los supuestos extraños que hemos mencionado en modo alguno entendemos que sean de ciencia-ficción, pues por desgracia la realidad supera cualquier cosa que podamos imaginar. Es por ello, que vamos a intentar modestamente buscar soluciones para las cuestiones aquí planteadas.

Es evidente que en virtud del contrato que es todo pacto sucesorio, el instituido va a estar amparado por las acciones que se deriven de los contratos, por lo que vamos a acudir al Código Civil como supletorio.

El art. 1261 C.C. establece los requisitos que han de concurrir en un contrato para que pueda considerarse tal y despliegue sus efectos jurídicos entre las partes: consentimiento, objeto cierto y causa.

Por tanto, si en esas disposiciones onerosas del instituyente con un tercero existe defecto en alguno de estos requisitos es evidente que el instituido podría ejercer las siguientes acciones, establecidas en el Código Civil:

- Nulidad. Se ejercita en los supuestos de traspaso de los límites que permite el ordenamiento jurídico para el ejercicio de la autonomía de la voluntad y en el caso de que el contrato entre el instituyente y el tercero carezca de los requisitos esenciales del 1261. El instituido como perjudicado en sus derechos puede soli- 
citar que se declare la nulidad de ese contrato, que tendría efectos ex tunc, como si nunca se hubiese celebrado. Su ejercicio es imprescriptible, porque al ser radicalmente nulo nunca ha producido efectos jurídicos, pero ha de solicitarse su declaración para que despliegue sus efectos erga omnes.

- Anulabilidad, nulidad relativa. Si no se ejercita en el plazo de caducidad de cuatro años el contrato deviene inatacable. Son los supuestos en que uno de los contratantes (para el caso el instituyente) ha sufrido un vicio de la voluntad o posee una capacidad de obrar restringida o, por ejemplo, se realiza la disposición onerosa por el instituyente con un tercero sin el consentimiento del instituido cuando la ley lo exigiera como necesario.

- Rescisión. Sería de aplicación la acción de rescisión cuando se haga la disposición en fraude de acreedores considerando, en ese caso, acreedor al sucesor de los bienes, ya que el fin perseguido es que no perciba aquel derecho expectante que se le ha conferido. El art. 1297 considera que existe siempre fraude cuando uno de los contratantes sea persona contra la que se hubiese dictado sentencia condenatoria en cualquier instancia o expedido mandamiento de embargo. Tal afirmación nos parece excesiva, pues no siempre y en todos los casos quien se encuentre en una de esas dos situaciones descritas ha de ser un defraudador nato, aunque tales circunstancias pueden servir para poner sobre aviso. Dicha acción, que es subsidiaria, tiene un plazo de prescripción de cuatro años.

- Simulación. En este caso se habría producido un engaño a los terceros al acto (instituido). Existen distintas posturas doctrinales sobre su naturaleza. Una gran parte de la doctrina y la Jurisprudencia lo ha enmarcado dentro de la teoría de la causa del negocio, y sobre ella debemos acudir a los arts. 1275 y 1276 del C.C. La acción es declarativa e imprescriptible.

-Daños y prejuicios del art. 1101 C.C. En este precepto se regula la culpa contractual derivada del contrato (en este caso pacto sucesorio) entre instituyente y sucesor. Existen muchos supuestos que permitirían su acción, sin que implique una acción fraudulenta o en abuso de derecho por el heredante. Así, en los casos en que el sucesor, como hemos referido en otros apartados, haya invertido esfuerzo y trabajo en el bien patrimonial que posteriormente se ve transformado o enajenado. Habría de entenderse que podría cuantificar y valorar ese esfuerzo o reclamar el capital invertido. También podría reclamarlos en el supuesto mencionado de que tras la disposición onerosa el importe 
o permuta respecto del bien sea inferior a la de la masa conferida al instituido.

- También entendemos que el instituido tendría acción personal en el caso de que el instituyente le transfiriese la masa patrimonial en la que le nombra sucesor por precio, ya que al no estar revocado el pacto tendría derecho post mortem a reclamar el dinerario abonado por el bien.

\section{VI.3. Conclusiones en torno a la actual regulación legal de la institución}

Como consecuencia del estudio realizado, pueden extraerse las siguientes conclusiones relativas a la regulación actual de la institución, así como a las necesidades que debería satisfacer una futura reforma legal:

1. ${ }^{a}$. Se ha intentado poner de manifiesto la falta de regulación de la Ley 3/1992 sobre los límites de acción del instituyente y el vacío legal existente sobre las acciones del instituido.

2. ${ }^{a}$. Entendemos que dicha circunstancia puede provocar situaciones difíciles que no siempre van a resolverse cómodamente a través del Código Civil, como Derecho común supletorio.

$3{ }^{a}$. En la elaboración de una nueva Ley civil vasca habría de tenerse en cuenta si la institución del pacto sucesorio es plenamente vigente y si puede sobrevivir a las nuevas circunstancias sociales que se plantean (por ejemplo, se nombra instituido/a a uno de los hijos/as y a su cónyuge, invirtiendo éste esfuerzo y dinero en el bien objeto del pacto, y luego se separan sin haberse revocado el pacto).

4. ${ }^{\text {a }}$. El Primer Anteproyecto previene de alguna manera esta cuestión a la usanza de la normativa de Aragón y Navarra, al establecer en su art. 105 el consentimiento cuando el pacto lo sea respecto de patrimonios productivos, pudiéndose realizar un esfuerzo mayor que dé mayores garantías al sucesor en los bienes.

5. . El avance de las nuevas tecnologías, de las comunicaciones, etc., hace que hoy en día los negocios familiares posean unas características físicas muy distintas a las tradicionales, por lo que se hace necesario tanto adaptar las instituciones y derechos históricos que lo permitan como eliminar, en su caso, de la actual normativa aquello que carezca de virtualidad práctica, pues el Derecho ha de ser, por naturaleza algo vivo, dinámico y práctico. 


\section{Bibliografía}

Albaladejo García, Manuel, El artículo 869 del Código Civil, en Revista de Derecho Privado, 1980.

Castán Tobeñas, José, Derecho Civil Español, Común y Foral, Tomo VI, Volumen I y II, Reus, Madrid, 1978.

Celaya IBARRA, Adrián, Derecho Foral y Autonómico Vasco, Tomo I, Universidad de Deusto, Bilbao, 1984.

-, Comentarios al Código Civil y Compilaciones Forales, coord. AlbaladeJo García, Manuel, Revista de Derecho Privado, Tomo XXVI, Edersa, Madrid, 1978.

Díez-Picazo, Luis y Gullón Ballesteros, Antonio, Sistema de Derecho Civil, Vol. II, Tecnos, Madrid, 1979.

Marín Castán, Francisco, Comentario del Código Civil, coord. GIL DE LA SIERRA, Ignacio, Volumen 5, Bosch, Barcelona, 2000.

MONASTERIO ASPIRI, Itziar, Los pactos sucesorios en el derecho vizcaino, Universidad de Deusto-Diputación Foral de Bizkaia, Bilbao, 1994.

Roca Sastre-Muncunill, Luis, Derecho de Sucesiones, Tomo III, Bosch, Barcelona, 1989.

RocA TRÍAs, Encarna, «Lección 12» en Derecho civil, Derecho de sucesiones, coord. CAPIlla Roncero, R., Tirant lo Blanch, Valencia, 1999.

LEY de 30 de julio de 1959. La Compilación de Derecho Civil Foral de Vizcaya y Alava.

LEY 3/1992 de 1 de junio, de Derecho Civil Vasco.

LEY 15/1967, de 8 de abril, sobre Compilación del Derecho Civil de Aragón.

DeCRETo Legislativo 79/1990, de 6 de septiembre, por el que se aprueba el Texto Refundido de la Compilación del Derecho Civil de las Islas Baleares.

LEY 1/1973, de 1 de marzo, por la que se aprueba la Compilación del Derecho Civil Foral de Navarra.

LEY 40/1991, de 30 de diciembre. Código de Sucesiones por causa de muerte en el Derecho Civil de Cataluña.

LEY 147/1963 de 2 de diciembre, sobre Compilación del Derecho Civil de Galicia.

LEY 49/1981 de 24 de diciembre del Estatuto de la explotación agraria y de los agricultores jóvenes.

LEY 19/1995 de 4 de julio de Modernización de las Explotaciones agrarias. 